\title{
Detection of Diseases in Oil Palm Plantations in the Brazilian Amazon through Orbital Image
}

\author{
João Almiro Corrêa Soares ${ }^{1}$, Artur Vinícius Ferreira dos Santos ${ }^{1}$, Paulo Roberto Silva Farias ${ }^{1}$, \\ Leidiane Ribeiro Medeiros ${ }^{2} \&$ Adriano Anastácio Cardoso Gomes ${ }^{1}$ \\ ${ }^{1}$ Universidade Federal Rural da Amazônia, Belém, Pará, Brazil \\ ${ }^{2}$ Specialization Program in Geoprocessing Applied to Agroecology and to the Use of Natural Resource, \\ Universidade Federal do Pará, Belém, Pará, Brazil \\ Corresponding author: João Almiro Corrêa Soares, Agronomy Graduation Program, Universidade Federal Rural \\ da Amazônia, Belém, Pará, Brazil. E-mail: joaoalmiro@gmail.com
}

Received: July 16, 2019 Accepted: February 5, $2020 \quad$ Online Published: March 15, 2020

doi:10.5539/jas.v12n4p138 URL: https://doi.org/10.5539/jas.v12n4p138

\begin{abstract}
The detection of diseases in oil palm crops in the Brazilian Amazon represents a great challenge for the management of this crop in Brazil. The plantations in the State of Pará provide inputs for the food, cosmetics, agro-energy and biofuel industries, supplying Brazilian markets. In recent years, several factors such as pests, diseases and climate have interfered in the development of oil palm in the region, generating the need to adopt new techniques to detect and monitor such issues. In this work, spectral enhancements were carried out by simple reflectance and vegetation indices for four plots cropped on Companhia Palmares da Amazônia (CPA) farm, owned by Agropalma S.A. company in the municipality of Acará, in the state of Pará. The results allowed the identification of expressive patterns minimum and maximum reflectances of the studied plots, correlating with occurrences of diseases. The EVI index showed an excellent correlation with the occurrence of diseases. However, the NDVI and SAVI indexes showed adequate adjustments with the occurrence of diseases in 2017. The areas corresponding to the L36 and H27 plots showed higher occurrences of diseases, based on the analysis of reflectance through vegetation indices. It is concluded that the reflectance enhancements, NDVI, SAVI and EVI obtained by orbital sensors are efficient in the detection of diseases in the plots. The results allowed the identification of diagnostic anomalies of stresses in the plots, either by disease or other factor, allowing the decision making in an adequate time, therefore avoiding large scale eradication in the extensive areas in commercial palm oil plantations in Brazil.
\end{abstract}

Keywords: Amazon, farming monitoring, oil palm, spectral analysis

\section{Introduction}

Oil palm (Elaeis guineenses Jacq.) is an oleaginous palm native to Africa, grown in large scale in the Brazilian Amazon, in areas that have already been deforested. In the region, approximately 207 thousand hectares of cropped area is totalized, about $88 \%$ of the Brazilian crop where the largest oil production is found (Abrapalma, 2018).

In Brazil and in the Brazilian Amazon, the state of Pará is the largest producer of oil palm, particularly in the municipalities of Acará, Baião, Bujaru, Concórdia do Pará, Igarapé-Açu, Moju, São Domingos do Capim, Tailândia, and Tomé-Açu. The region is favored by ideal agro-climatic conditions and governmental support provided by the Sustainable Palm Oil Production Program in Brazil (Alves et al., 2016).

Factors such as production and palm oil extraction rate are fundamental to the viability of crop investments, directly influencing the profitability of the companies that invest in this crop (Teles, 2014). Palm oil is obtained from the oil palm, which is an edible and balanced oil, extracted from the mesocarp, and the palm kernel oil, derived from the almond (Bergmann et al., 2013). The growing world's demand for these oils is related to the consumer market that uses them in the food, cosmetics, hygiene and cleaning, agro-energy and biofuel industries. In this context of demand, about $80 \%$ of the production is directed to the food industry, such as margarines, creams, ice cream, biscuits, chocolates, fillers and substitutes of cocoa butter and cooking oil (Abrapalma, 2018). 
Due to the increase in cropped areas and the recognized economic importance of the culture in the Brazilian Amazon, especially in the state of Pará (Brazil), there is a need for reliable, comprehensive, systematic and agile information on the oil palm, which has become even more crucial in the face of phytosanitary issues that strongly affect the productivity of these palms and decrease their expansion (Duarte et al., 2008; Pinho et al., 2016). Among these phytosanitary limitations, we highlight insects, drill pests (Rhynchophorus palmarum, Linnaeus, 1764; and Eupalamides cyparissias cyparissias Fabricius, 1776), defoliators (Opsiphanes invirae Hubner, 1818), and oil palm diseases, such Fatal Yellowing (FY), red ring disease (Bursaphelenchus cocophilus Cobb, 1919), sudden wilt (Phytomonas staheli McGhee and McGhee, 1979) and vascular wilt (Fusarium oxysporum f. sp. elaedis) (Flood, 2006; Maciel et al., 2015; Assis Costa et al., 2018; Nascimento et al., 2018; Martínez et al., 2019).

Most agronomic information related to the occurrence of diseases in Amazonian oil palm plantations is obtained manually and rudimentarily by means of field surveys performed by the so-called "pragueiros" or field agents, who range plant-to-plant, seeking the visual recognition of pests and diseases. As a result, work becomes expensive, time-consuming and subject to frequent mistakes. Such a model generally allows for late diagnosis, with no other curative action to be taken, resulting in destruction of the plant (Giese et al., 1975; Goodell, et al., 2014).

Among several techniques of aid for farm crop management, the use of remote sensing has shown promising results for rapid and efficient detection of diseased plants in small and large geographic areas (Naue et al., 2011; Zhang et al., 2019). It is a technology composed of sensors and platforms, capable of obtaining information from the surface without physical contact with it, and often at long distances, from satellites and manned aircraft. Thus, remote sensing has become an instrument of great potential, where its usefulness contributes in several studies such as vegetation, acting in precision agriculture through the monitoring and physiological and phenological studies of the plantation (Novo, 2010; Mahlein, 2016; Zhang et al., 2019).

For the evaluation and monitoring of agricultural crops, remote sensing allows spectral analyses through reflectance curves and vegetation indexes, qualifying this technique as relevant for agricultural management. Through the analysis of spectral parameters of the vegetation, with more attention to the visible and near infrared, the several vegetation indices allow the differentiation in several points of the agricultural and forest cultivation (Ponzoni \& Shimabukuro, 2007).

The understanding of the spectral behavior allows to extract information of the vegetation distribution, canopy structure, phenological state, stress conditions, nutrient deficiency, among others (Ponzoni et al., 2012). The NDVI is an index that can be used in studies related to vegetation dynamics with more homogeneous values, besides being a good estimator of biomass. However, it can be influenced by atmospheric interferences (Souza \& Silva, 2016).

By considering the successive occurrences of pests and diseases in the oil palm in recent years (Maciel et al., 2015; Torres et al., 2016; Murguía-González et al., 2018; Martínez et al., 2019), and the great difficulties of their containment in the current management routines, it is important to consolidate a technique that is efficient and shows a rapid response for the detection of diseases in the extensive plantations of the region, starting with the present experiment carried out in plots in the municipality of Acará. Thus, this paper evaluates the efficiency of the Sentinel-2A MSI orbital sensor for the detection of anomalies caused by diseases in the palm oil crop in the municipality of Acará, representative of the crops in the Brazilian Amazon.

\section{Methodology}

\subsection{Study Area}

The study area is owned by Agropalma S.A., in municipality of Acará, located in the mesoregion of the Northeastearn Para and microregion of Tomé-Açu, about $114 \mathrm{~km}$ away from Belém, capital of the state of Pará (PA), in the Brazilian Amazon (Figure 1). It has an estimated population of 55,513 thousand inhabitants and a territorial area of 4,343.550 $\mathrm{km}^{2}$ (IBGE, 2018a). The climate of the municipality corresponds to the megathermal, Am type according to the classification of Köppen, that is, hot and wet equatorial, with propensity to agropastoral activities. Besides, the favorable climate and abundance of water allowed many projects aimed at the production of palm oil. Rainfall ranges from 2,000 to 3,000 mm annually, with higher occurrences between December and April. The soil type is predominantly Yellow Latosol and medium clayey texture. This study was carried out in an area of cropped plots, located by the geographic coordinates $02^{\circ} 18^{\prime} 10.1^{\prime \prime} \mathrm{S}$ and $48^{\circ} 39^{\prime} 40^{\prime \prime} \mathrm{W}$.

The experiments were carried out in the L30, L36, H25 and H27 plots, with individual areas of approximately 36 hectares owned by Companhia Palmares da Amazônia (CPA) company belonging to Agropalma S.A. (Figure 1), 
classified as mature conventional type crops at approximately 16 years of age, arranged in an equilateral triangle with spacing of $9 \times 9 \mathrm{~m}$.

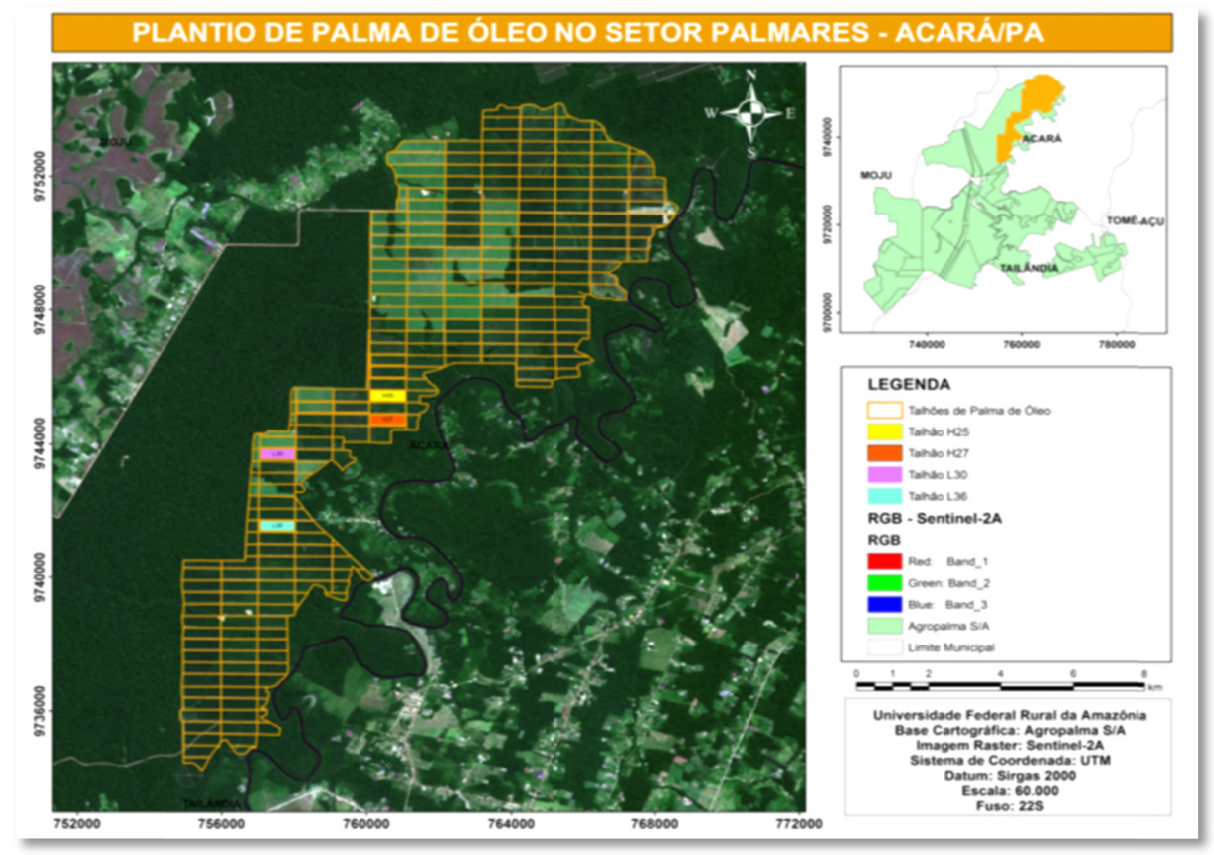

Figure 1. Geographic localization of the study area

\subsection{Experimental Database}

\subsubsection{Sentinel-2A MSI (Multi Spectral Instrument)}

The Sentinel-2A image files, MSI (Multi Spectral Instrument) sensor were made available by Earth Explore USGS, dated July 25, 2017. The following bands were acquired: B2 (Spectral range Blue $-458-523 \mathrm{~nm} / 490 \mathrm{~nm}$ ) with sensitivity to dispersion of vegetation aerosols; B3 (Green spectral range- $543-578 \mathrm{~nm} / 560 \mathrm{~nm}$ ) sensitive to total chlorophyll of vegetation; B4 (Red spectral range- $650-680 \mathrm{~nm} / 665 \mathrm{~nm}$ ) sensitive to maximum absorption of chlorophyll; B8 (NIR spectral range- $785-900 \mathrm{~nm} / 842 \mathrm{~nm}$ ) sensitive to healthy vegetation and with full leaf structure; and B11 (Swir range-1565-1655 nm/1610 nm) sensitive to vegetation enhancement and exposed soil. Except for B11, all images were acquired by 10-m spatial resolution and low percentage of clouds.

\subsubsection{Phytosanitary and Farming Data}

It was made available for the present study, the database of occurrences of diseases arranged in spreadsheets produced by the phitosanitary sector of Agropalma S.A., referring to the occurrences of yellow and red wing infected plants and eliminated per between the years of 2013 and 2018.

\subsection{Image Pre-processing}

The Sentinel-2A images were processed through the following steps: 1) atmospheric correction; 2) transformation to 8 bits $(256 \mathrm{NC})$; 3) georectification with 29 control points in the plot; 4) transformation of digital numbers $(\mathrm{DN})$ into apparent reflectance values; and 5) generation of vegetation indices and reflectance images. The data processing phase was carried out at the Laboratory of Geoprocessing, Spatial Analysis and Satellite Monitoring (LAGAM) of the Federal Rural University of Amazonia, in Belém, state of Pará. Field work in the study area was carried out on February 27, 2018, and consisted in the collection of control points and verification of the records of diseases in the evaluated plots.

\subsection{Vegetation Index Generation}

Vegetation indexes were extracted for four plots of the oil palm management area: L30, L36, H27 and H25. Three vegetation indexes were evaluated: Normalized Difference Vegetation Index (NDVI), Soil Adjusted Vegetation Index (SAVI) and Enhanced Vegetation Index (EVI). 
The Normalized Difference Vegetation Index (NDVI) is a spectral enhancement resulting from the combination of reflectance levels of red and infrared spectral bands. The NDVI, proposed by Rouse et al. (1973) was calculated through the following formula:

$$
\mathrm{NDVI}=\frac{\rho_{\mathrm{NIR}}-\rho_{\mathrm{RED}}}{\rho_{\mathrm{NIR}}+\rho_{\mathrm{RED}}}
$$

Where, $\rho$ NIR is the reflectance of the vegetation in the near infrared band and $\rho$ RED is the vegetation reflectance in the red band. Leaf reflectivity in the NIR stems is the result of the presence of intracellular spaces in its structure, and the larger the number of space within the leaf, the greater the radiation reflectivity (Jackson et al., 1983).

Soil-Adjusted Vegetation Index (SAVI) is an improvement on NDVI, proposed by Heute et al. (1988). It minimizes the effects of soil that partly influences NDVI, allowing the increase in the value of vegetation indices, especially in canopies with average levels of green cover. The constant " $L$ " ranges from 0 to 1 , according to the density of the vegetation. Thus, for low-density vegetation cover, the factor $\mathrm{L}$ is 1.0 ; medium coverage plant density, the factor will be 0.5 ; and for high densities, the L factor will be 0.25 . The index proposed by Huete et al. (1988) is calculated through the formula:

$$
\mathrm{SAVI}=\frac{\left(1+\mathrm{L}_{\mathrm{S}}\right)\left(\rho_{\mathrm{NIR}}-\rho_{\mathrm{RED}}\right)}{\left(\mathrm{L}_{\mathrm{S}}+\rho_{\mathrm{NIR}}+\rho_{\mathrm{RED}}\right)}
$$

Where, $\rho$ NIR is the near infrared band, $\rho$ RED is the red band and $L$ is the adjustment factor for the canopy substrate.

The Enhanced Vegetation Index (EVI), developed by Huete et al. (1997), seeks to improve vegetation sign by reducing soil and atmospheric interferences. It is very sensitive in regions with high biomass concentration. It is based on the following calculation:

$$
\mathrm{EVI}=\mathrm{G} \times \frac{\left(\rho_{\mathrm{NIR}}-\rho_{\mathrm{RED}}\right)}{\left(\rho_{\mathrm{NIR}}+\mathrm{C} 1^{*} \rho_{\mathrm{RED}}-\mathrm{C} 2^{*} \rho_{\text {blue }}+\mathrm{L}\right)}
$$

Where, $\rho$ NIR is the near infrared band, $\rho$ RED is the band of red, $\rho$ Blue is reflectance in the blue region, $G$ is the gain factor, $\mathrm{C} 1$ and $\mathrm{C} 2$ are adjustment coefficients for the aerosol effect of the atmosphere and $\mathrm{L}$ is the adjustment factor for the canopy substrate.

\section{Results and Discussion}

\subsection{Spectral Characterization Through Reflectance Enhancement}

Values of average reflectance were extracted from the L30, L36, H25 and H27 plots in Sentinel-2A images (Figure 2) (Table 1). The spectral band in the red band (RED) showed a lower reflectance average in the four plots, therefore, a higher absorption, indicating a RED radiation reception pattern for the plots due to the presence of photosynthetic pigments. However, the H25 plot displayed an anomalous pattern in relation to the other plots, with a greater reduction of the RED absorption, resulting in a strong collapse of chlorophyll and consequently an abnormal functioning of the plant, which is a response of the presence of diseases, pests or nutritional deficiency. The L30, L36 and H27 plots also showed low RED absorption.

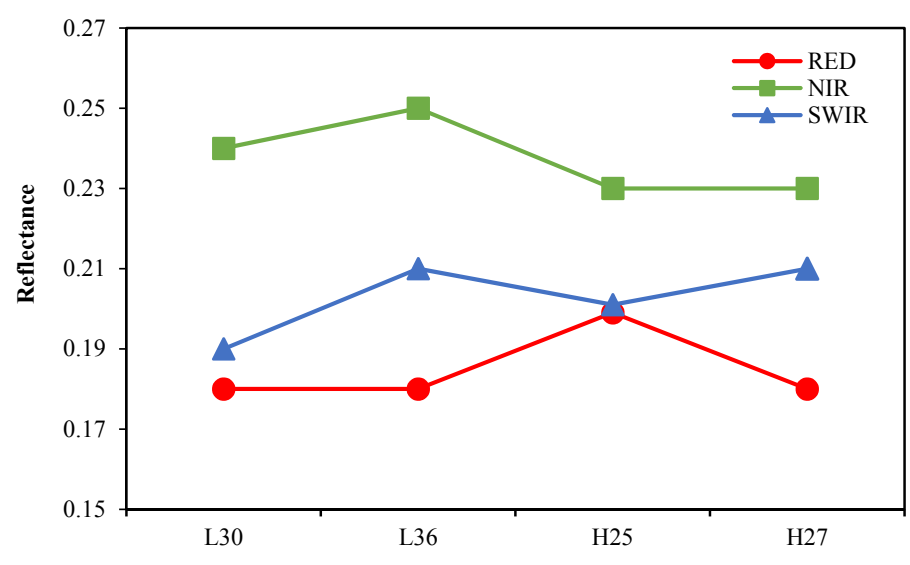

Figure 2. Spectral characterization by reflectance enhancement of oil palm in L30, L36, H25 and H2 plots 
Table 1. Average reflectance values of oil palm in L30, L36, H25 and H27 plots

\begin{tabular}{lllll}
\hline Bands & L30 & L36 & H25 & H27 \\
\hline RED & 0.18175 & 0.17681 & 0.20787 & 0.17967 \\
NIR & 0.24479 & 0.25660 & 0.22831 & 0.23021 \\
SWIR & 0.19833 & 0.21872 & 0.20145 & 0.21092 \\
\hline
\end{tabular}

The high reflectance in the NIR band refers to the strong interaction between radiation and internal structure of the leaves of the oil palm, common to the vegetation. It can be seen in the Figure 2 and Table 1 that the standard reflectance in NIR is very pronounced in L36 plot, an indicative of greater vegetative vigor. However, the H25, H27 and L30 plots showed a low reflectance, so it can be inferred that there was more deterioration of the cellular structure of the oil palm. When related to oil palm sanity, the short-wave infrared (SWIR) band shows similar behavior to the NIR (Figure 2 and Table 1), corroborating with the low reflectance observed in the H25 and L30 plots and better vegetative vigor in L36. These analyses are confirmed by the incidence of infected plants in the plots (Figure 4).

Thus, this spectral characterization represents a viable technique for the detection of spectral anomalies, indicative of diseases, which were only identified with long field and laboratory works (Amaral et al., 2009).

Table 1 shows that the reflectances in the RED band, in the $\mathrm{H} 25$ and $\mathrm{H} 27$ plots, considered with a higher degree of infection, are higher than those with healthy plants. The reflectance in the NIR region for more infected plots is lower than for areas with healthy plants (L30 and L36). This evidences that the contrast between the leaf reflectance in the RED and NIR bands can characterize the unequivocal presence of anomalies or not in the oil palm.

\subsection{Detection of Diseases in the Oil Palm Through Vegetation Indexes}

The use of vegetation indices in the monitoring of oil palm plantations will allow the early detection of anomalies associated with a variety of causes, including infection caused by red ring and fatal yellowing diseases, pests, water stress or nutritional deficiency. From 2013 to 2017, the incidence of plants infected with Fatal Yellowing (AF) increased, and in 2017, the highest occurrences (Figure 3) were observed. The application of the technique allowed to determine priority areas for emergency intervention in the crop management.

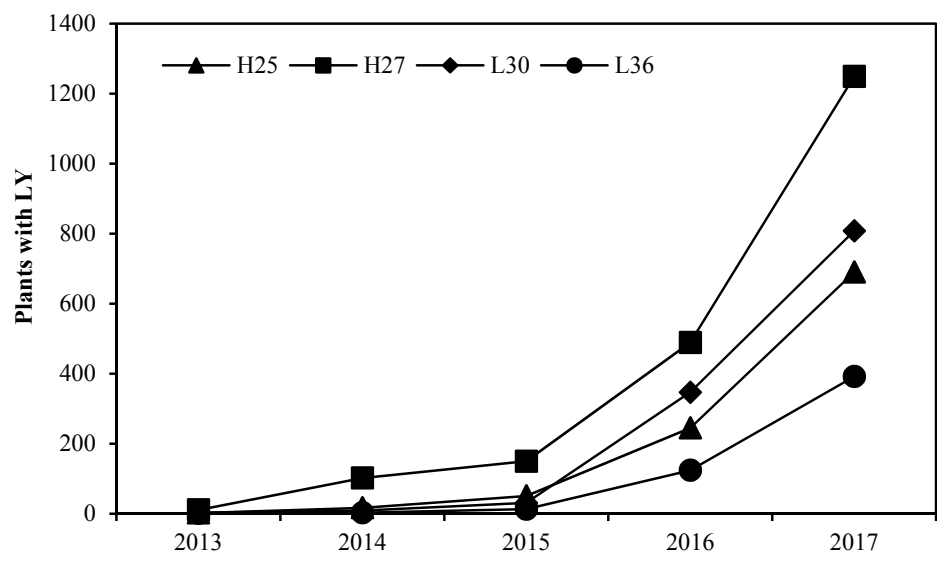

Figure 3. Fluctuation of the incidence of plants infected with Lethal Yellowing (LY) from 2013 to 2017, in oil palm plots L30, L36, H25 and H27, Acará, Brazil

The three indexes evaluated in this study allowed the identification of infected plants by any collapse factor, mainly caused by the diseases. In the four evaluated plots, anomalies referring to different symptoms or combination of symptoms were detected, thus, highlighting the occurrence of fatal yellowing. In this area of study, the width of canopies ranged from 8 to 16 meters for the adult plants, which generated a suitable pattern for area detection, compatible with the spatial resolution of the Sentinel-2A and the scale of this mapping. It was assumed that high index values (NDVI, SAVI and EVI) would be associated with increased photosynthetic activity and therefore, they could be used to discard the occurrence of infected plants (Wulder et al., 2006b). 
By considering the moment when the plant is not healthy, it tends to respond out the normal pattern of its levels of reflection and absorption in the leaf areas, therefore evidencing that the photosynthetic level and the absorbed radiation were affected. Modeling of vegetation indices is based on the opposite behavior of leaf reflectance in the RED band, that is, the higher the leaf density, the lower the reflectance as a function of the radiation absorption through the photosynthetic pigments, and the higher the plant density, the greater the reflectance in the different layers of the leaves (Boratto et al., 2013).

The NDVI data were discretized in the four plots, L30, L36, H25 and H27 for 2017, in order to detect infected areas in the mature oil palm. Results obtained in the NDVI, which are expressed with high reflectance in all plots, especially L36 and L30, show high maximum and minimum values (Figure 4).

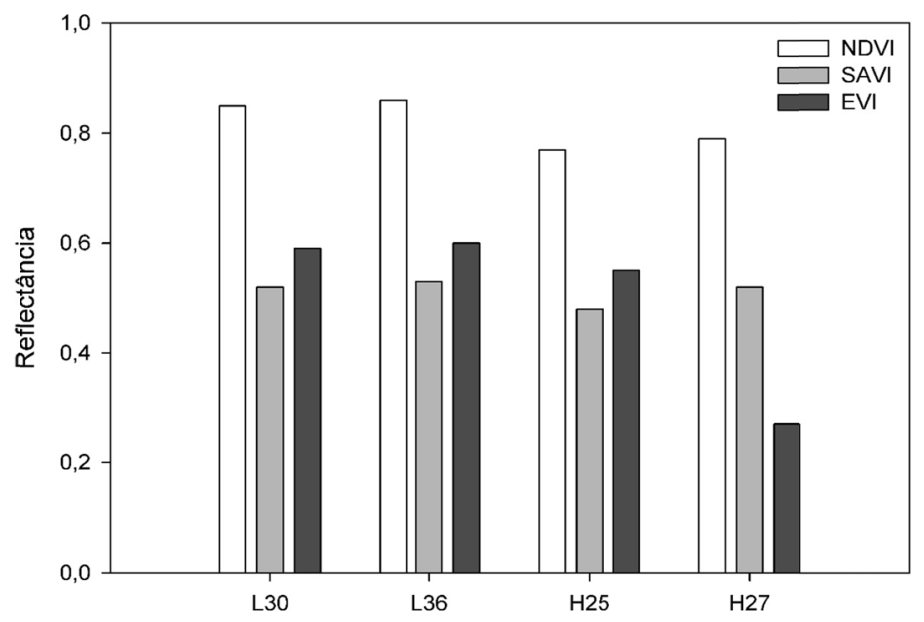

Figure 4. NDVI, SAVI and EVI in oil palm plots L30, L36, H25 and H27

The spectral pattern allows to infer a low occurrence of diseases in the dates prior to this experiment. However, for the plots H25 and H27 (Figure 5), lower values of maximum and minimum reflectance of NDVI are evident, with the minimum limits that do not allow the attribution of occurrence of diseases.
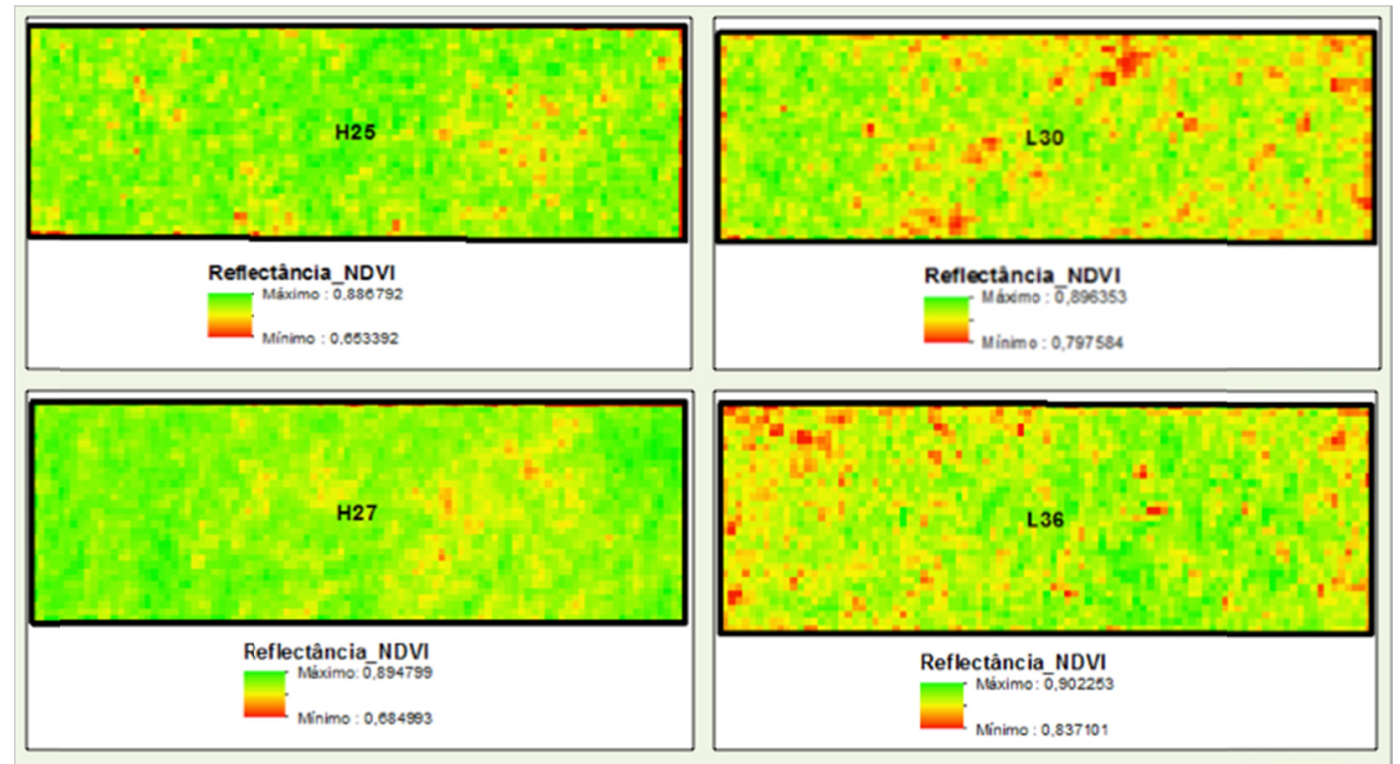

Figure 5. NDVI intensity spatial distribution in oil palm plots L30, L36, H25 and H27 in conventional oil palm crops, Acará (PA), Brazil 
Visualization of the SAVI maps highlighted low reflectance areas, which were significant for the diagnosis of disease, especially in the L30 and $\mathrm{H} 27$ plots, with maximum and minimum SAVI values pointing to anomalies in these areas (Figure 6). It can be observed that SAVI maintained an excellent correlation with the occurrences of FA observed in Figure 4. Regarding NDVI, SAVI showed better discrimination of impacted zones and intensity of occurrences. This SAVI performance may be associated to the fact that this index minimizes the effects of soil in the areas of the plots since an increase in the diagnosis of diseases in the last years, in some cases, resulted in the eradication of some plants.
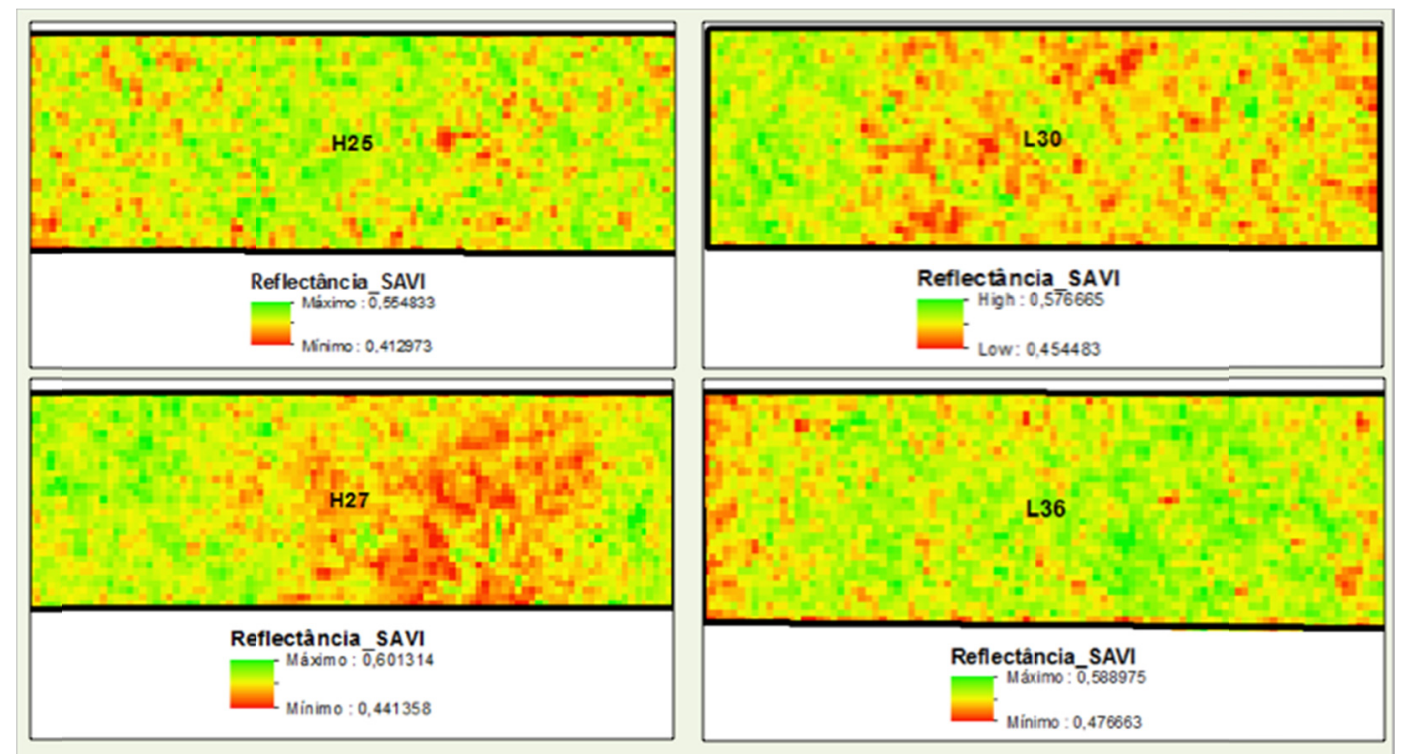

Figure 6. SAVI spatial distribution intensity in oil palm plots L30, L36, H25 and H27 in conventional palm oil crops, Acará (PA), Brazil

The analysis of the EVI reflectance (Figure 3) clarifies that the plot that presented the greatest anomaly representative of diseases was $\mathrm{H} 27$. Figure 7 strongly emphasizes the pixel areas with low reflectance in the EVI images in the L30 and H27 plots, indicative of the high presence of diseases. There were 1249 and 808 documented cases of fatal yellowing in H27 and L30 plots, respectively (Figure 3). In comparison to NDVI and SAVI, the EVI showed an excellent performance in the discrimination of the most impacted zones as EVI improved the vegetation signal, attenuating the influence of the atmosphere and the soil on the canopy of the oil palm in this region in the Amazon. 


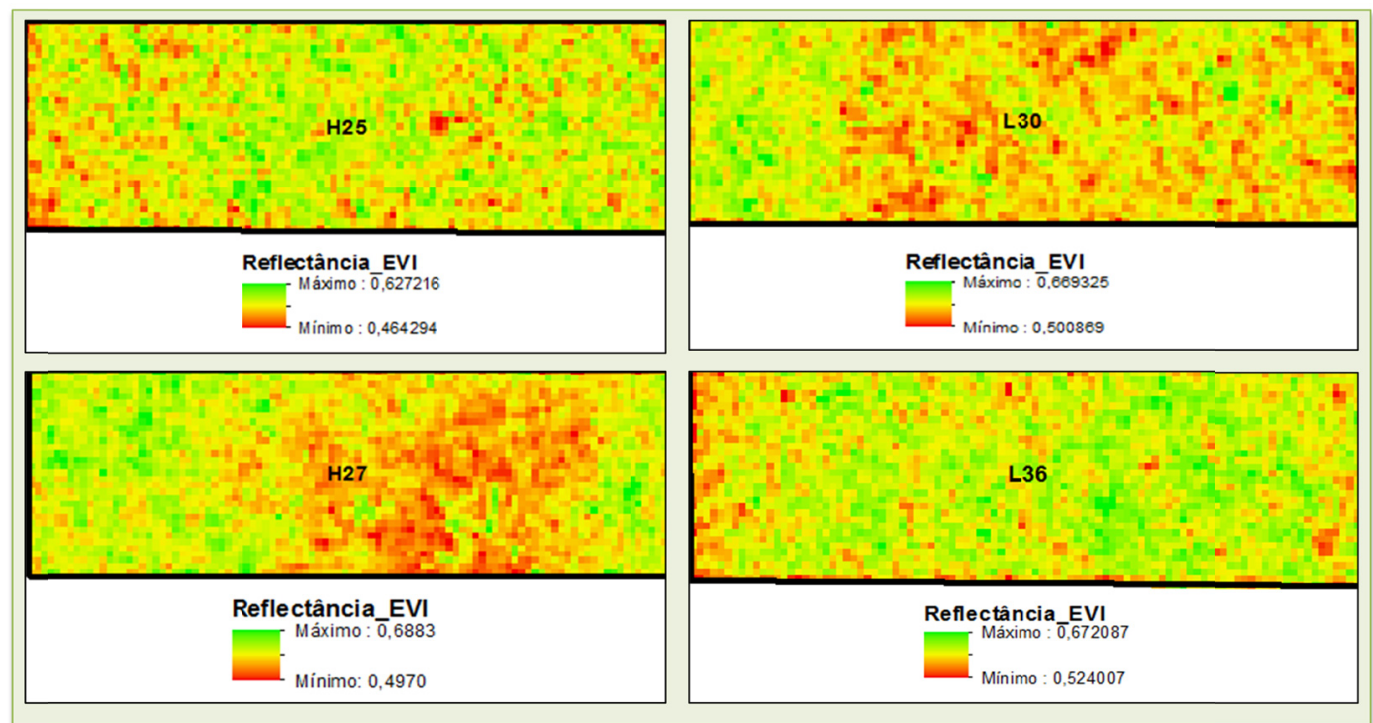

Figure 7. Spatial distribution of EVI intensity in oil palm L30, L36, H25 and H27 plots in conventional oil palm crops, Acará (PA), Brazil

According to Santos et al. (2011), vegetation index analysis of orbital images provides general accuracy of about $80 \%$ for the mapping of disease infection in oil palm crops. The results obtained by this experiment will allow the definition of a practical methodology or a model for the monitoring of the oil palm crop in the Brazilian Amazon. The favorable correlation between vegetation index reflectance levels and occurrence of disease in the assessed area shows the potential of Sentinel-2A images, confirmed by the clear expression of L36 and H27 reflectance extremes. This situation allows to minimize or confirm the occurrence of diseases.

\section{Conclusions}

This study approached the spectral enhancement through vegetation indices to determine the unequivocal viability of remote sensing techniques in the detection of diseases in oil palm. In this approach, Sentinel 2-A orbital images were effective in monitoring and indicating areas for detailed assessment, saving time and financial resources in oil palm management. Medium-resolution orbital images can be widely used to detect areas with disease infection or occurrence of pests in the oil palm. Enhancements through vegetation indices can systematically discriminate the areas with healthy and infected plants.

Enhancements through simple reflectance as well as NDVI, SAVI and EVI were efficient in the detection of diseases in the oil palm, especially the detection in L30 and H27 plots in the study area. The curves generated through NDVI, SAVI and EVI proposed an analysis that allows the identification of diagnostic anomalies of stresses in the plots, either by disease or other factor, allowing adequate time for remediation actions that avoid plant eradication.

Other studies in this direction for crops in Brazil should enable spectral detailing of the diseased and healthy oil palm, the different maturity stages and genetic varieties in the Brazilian Amazonian crops. This characterization should improve the accuracy of detection methods through spectral analysis.

\section{References}

Abrapalma. (2018). Associação Brasileira de Produtores de Óleo de Palma. Retrieved from http://www.abrapalma.org/en/palm-oil-in-everyday-life

Alves, R. N. B., Modesto Júnior, M. S., Magalhães, J., \& Bandeira, B. (2016). Análise comparativa dos custos de implantação do cultivo de dendê solteiro e consorciado com mandioca. Amazônia: Ciência \& Desenvolvimento, 12(22), 9-20.

Amaral, C. H., Longhitano, G. A., \& Almeida, T. I. R. (2009). Estudo de fisiologia da vegetação com uso de imagem hiperespectral (pp. 2515-2522). XIV Simpósio Brasileiro de Sensoriamento Remoto, Natal. Anais... INPE. 
Assis Costa, O. Y., Tupinambá, D. D., Bergmann, J. C., Barreto, C. C., \& Quirino, B. F. (2018). Fungal diversity in oil palm leaves showing symptoms of Fatal Yellowing disease. PLoS ONE, 13(1). https://doi.org/ 10.1371/journal.pone.0191884

Bergmann, J. C., Tupinamba, D. D., Costa, O. Y. A., Almeida, J. R. M., Barreto, C. C., \& Quirino, B. F. (2013). Biodiesel production in Brazil and alternative biomass feedstocks. Renew Sust Energ Rev., 21, 411-20. https://doi.org/10.1016/j.rser.2012.12.058

Boratto, I. M. de P., \& Gomide, R. L. (2013). Aplicação dos índices de vegetação NDVI, SAVI e IAF na caracterização da cobertura vegetativa da região Norte de Minas Gerais. XVI Simpósio Brasileiro de Sensoriamento Remoto, Foz do Iguaçu. Anais... INPE.

Duarte, A. G., Lima, I. S., Araújo Jr. J. V., Duarte, A. G. Albuquerque, A. L. S., \& Cruz, M. M. (2008). Disposição do nematoide Bursaphelenchus cocophilus (Cobb) baujard, em coqueiros portadores da doença anel-vermelho. Revista Brasileira de Fruticultura, 30(3), 622-627. https://doi.org/10.1590/S0100-29452 008000300010

Flood, J. (2006). A Review of Fusarium Wilt of Oil Palm Caused by Fusarium oxysporum f. sp. elaeidis. Phytopathology, 96(6), 660-662. https://doi.org/10.1094/PHYTO-96-0660

Giese, R. L., Peart, R. M., \& Huber, R. T. (1975). Pest Management. Science, 187, 1045-1052.

Goodell, P. B., Zalom, F. G., Strand, J. F., Wilen, C. A., \& Windbiel-Rojas, K. (2014). Over 35 years, integrated pest management has reduced pest risks and pesticide use. California Agriculture, 68(04), $153-157$. https://doi.org/10.3733/ca.v068n04p153

Huete, A. R. (1988). A soil-adjusted vegetation index (SAVI). Remote Sensing of Environment, 25, $295-309$. https://doi.org/10.1016/0034-4257(88)90106-X

Huete, A. R., Liu, H. Q., Batchily, K., \& Van Leeuwen, W. (1997). A Comparison of Vegetation Indices over a Global Set of TM Images for EOS-MODIS. Remote Sensing of Environment, 59, 440-451. https://doi.org/ 10.1016/S0034-4257(96)00112-5

IBGE (Instituto Brasileiro de Geografia e Estatística). (2018a). Cidades. Retrieved from https://cidades.ibge. gov.br/brasil/pa/acara/panorama

Jackson, R. D., Slater, P. N., \& Pinter, P. J. J. R. (1983). Discrimination of growth and water stress in wheat by various vegetation indices through clear and turbid atmospheres. Remote Sensing of Environment, 13, 187-208. https://doi.org/10.1016/0034-4257(83)90039-1

Maciel, A. S., Garbelotto, T. A., Winter, I. C., Roell, T., \& Campos, L. A. (2015). Description of the males of Lincus singularis and Lincus incisus (Hemiptera: Pentatomidae: Discocephalinae). Zoologia (Curitiba), 32(2), 157-161. https://dx.doi.org/10.1590/S1984-46702015000200007

Mahlein, A. K. (2016). Plant Disease Detection by Imaging Sensors-Parallels and Specific Demands for Precision Agriculture and Plant Phenotyping. Plant Disease, 100(2), 241-251. https://oi.org/10.1094/ PDIS-03-15-0340-FE

MAPA (Ministério da Agricultura, Pecuária e Abastecimento do Brasil). (2018). Diagnóstico da Produção Sustentável da Palma de Óleo no Brasil. Brasília: MAPA/ACE.

Martínez, L. C., Plata-Rueda, A., Rodríguez-Dimaté, F. A., Campos, J. M., Santos Júnior, V. C., Rolim, G. D. S., ... Serrão, J. E. (2019). Exposure to Insecticides Reduces Populations of Rhynchophorus palmarum in Oil Palm Plantations with Bud Rot Disease. Insects, 10, 111. https://doi.org/10.3390/insects 10040111

Murguía-González, J., Landero-Torres, I., Leyva-Ovalle, O. R., Llarena-Hernández, R. C., Presa-Parra, E., \& García-Martínez, M. A. (2018). Efficacy and Cost of Trap-Bait Combinations for Capturing Rhynchophorus palmarum L. (Coleoptera: Curculionidae) in Ornamental Palm Polycultures. Neotropical Entomology, 47, 302-310. https://doi.org/10.1007/s13744-017-0545-8

Nascimento, S. V., Magalhães, M. M., Cunha, R. L., Costa, P. H. O., Alves, R. C. O., Oliveira, G. C., \& Valadares, R. B. S. (2018). Differential accumulation of proteins in oil palms affected by fatal yellowing disease. PLoS ONE, 13(4). https://doi.org/10.1371/journal.pone.0195538

Naue, C. R., Marques, M. W., Lima, N. B., \& Galvíncio, J. D. (2011). Sensoriamento remoto como ferramenta aos estudos de doenças de plantas agrícolas: uma revisão. Revista Brasileira de Geografia Física, 3(3), 190-195. https://doi.org/10.5935/1984-2295.20100018 
Novo, E. M. L. de M. (2010). Sensoriamento Remoto: Princípios e Aplicações (4th ed.). São Paulo: Blucher.

Pinho, R. C., Farias, P. R. S., Rodrigues, K. C. V., Tinôco, R. S., Dos Santos, A. V. F., \& Marssena, R. T. P. (2016). Distribuição espacial de Rhynchophorus palmarum em palma de óleo no Estado do Pará, Amazônia. Revista de Ciências Agrárias, 59(1), 22-31. https://doi.org/10.4322/rca.2116

Ponzoni, F. J., \& Shimabukuro, Y. E. (2007). Sensoriamento remoto aplicado ao estudo da vegetação (1st ed., Vol. 1, p. 135). São José dos Campos: Parêntese.

Ponzoni, F. J., Shimabukuro, Y. E., \& Kuplich, T. M. (2012). Sensoriamento Remoto da Vegetação (2nd ed., Vol. 1, p. 176). São Paulo: Oficina de Textos.

Rouse, J. W., Haas, R. H., Schell, J. A., \& Deeering, D. W. (1973). Monitoring vegetation systems in the Great Plains with ERTS (Earth Resources Technology Satellite) (pp. 309-317). Third Erts (Earth Resources Technology Satellite) Symposium, Greenbelt, Md, NASA (National Aeronautics and Space Administration), 1973, São Paulo. Anais... São Paulo, Brazil.

Santos, H., Gunawan, T., Jatmiko, R. H., Darmosarkoro, W., \& Minasny, B. (2011). Mapping and identifying basal stem rot disease in oil palms in north sumatra with QuickBird imagery. Precision Agriculture, 12, 233-248. https://doi.org/10.1007/s11119-010-9172-7

Souza, J. F., \& Silva, R. M. (2016). Análise de perfis temporais de NDVI e EVI em diferentes usos do solo no município de Goiana-PE. OKARA: Geografia em Debate, 10(3), 604-619.

Teles, D. A. A. (2014). Características físicas e rendimento mensal em óleo de cachos de duas cultivares de dendezeiro cultivadas, sob irrigação, no Cerrado do Distrito Federal (76f., Dissertação (Mestrado em Agronomia), Universidade de Brasília, Brasília).

Torres, G. A., Sarria, G. A., Martinez, G., Varon, F., Drenth, A., \& Guest, D. I. (2016). Bud rot caused by Phytophthora palmivora: A destructive emerging disease of oil palm. Phytopathology, 106, 320-329. https://doi.org/10.1094/PHYTO-09-15-0243-RVW

Wulder, M., White, J., Bentz, B., \& Ebata, T. (2006). Augmenting the existing survey hierarchy for mountain pine beetle red attack damage with satellite remotely sensed data. Forestry Chronicle, 82(2), 187-202. https://doi.org/10.5558/tfc82187-2

Zhang, T., Su, J., Liu, C., \& Chen, W. (2019). Potential Bands of Sentinel-2a Satellite for Classification Problems in Precision Agriculture. International Journal of Automation and Computing, 16(1), 16-26. https://doi.org/ $10.1007 / \mathrm{s} 11633-018-1143-\mathrm{x}$

\section{Copyrights}

Copyright for this article is retained by the author(s), with first publication rights granted to the journal.

This is an open-access article distributed under the terms and conditions of the Creative Commons Attribution license (http://creativecommons.org/licenses/by/4.0/). 